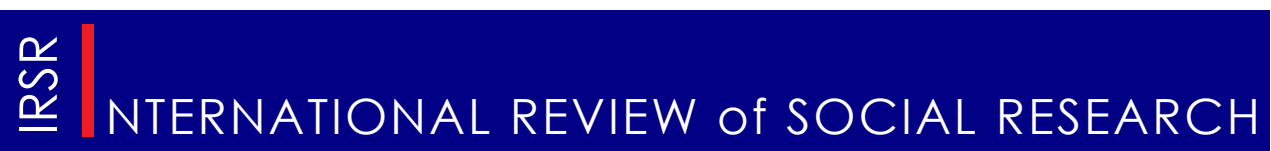

Volume 3, Issue 2, June 2013, 7-28

International Review of Social Research

\title{
Managing Distress, Effecting \\ Empowerment: \\ A Conversation Analytic Case Study of \\ a Call to the Home Birth Helpline
}

\author{
Rebecca SHAW $\cdot$ \\ Institute of Health and Wellbeing \\ University of Glasgow \\ Celia KITZINGER \\ Department of Sociology \\ University of York
}

\begin{abstract}
One of the most pressing concerns for many helpline staff is how to manage overt forms of distress and anxiety manifest in 'troubles talk', while also encouraging (or 'empowering') callers to take action to change the conditions that are creating the distress. Based on an audio-recording of a single call to a Home Birth helpline (drawn from a corpus of 80 such calls), we use conversation analysis to explore how the call-taker negotiates the tension between managing the caller's distress about her scheduled hospital labour (the 'presenting problem'), while also encouraging her to arrange a home birth (the 'problem solution'). We focus on the work the call-taker does to position herself as troubles-talk recipient, while also ensuring that by the end of the encounter the caller has received the information and advice she needs to take action to organise her home birth.
\end{abstract}

Keywords: compliments, conversation analysis, empowerment, helplines, support work, troubles talk.

One of the most pressing concerns for staff on helplines (and in other services) providing emotional and psychological support, is how to manage overt forms of distress and anxiety made manifest in 'troubles talk', while at the same time encouraging (or 'empowering') callers to take action to change the conditions that are creating the distress. This is raised as a concern by helpline calltakers across a range of helplines (e.g. Hepburn and Potter, 2007), including the one we focus on here, the Home Birth helpline, a UK-based, voluntary organisation (advertised in books and magazines on pregnancy and childbirth)

-e-mail: rebecca.shaw@glasgow.ac.uk. Rebecca Shaw is a Lecturer in the Institute of Health and Wellbeing at the University of Glasgow. Celia Kitzinger is Professor of Conversation Analysis, Gender \& Sexuality in the Department of Sociology at the University of York and Director of the Chronic Disorders of Consciousness Research Group. Acknowledgments: We are very grateful to the call-taker (who wishes to be named as Sheila Kitzinger) and to the callers on the Home Birth helpline who gave permission for their calls to be recorded for the purposes of research and training. This work would not have been possible without their input. The data set formed part of the first author's Ph.D. research, supervised by the second author, and funded by an Economic and Social Research Council research studentship. Sue Wilkinson and two anonymous reviewers gave invaluable feedback on this article. 
offering support and information for women planning a home birth. One of the helpline's stated aims is to 'empower women around home birth' (www.sheilakitzinger.com; Kitzinger and Kitzinger, 2007). According to the literature on (psychological) empowerment, this refers to developing clients' perceptions of personal control, a proactive approach to life, and a critical understanding of the sociopolitical environment. It includes 'beliefs that goals can be achieved, awareness about resources and factors that hinder or enhance one's efforts to achieve those goals, and efforts to fulfill the goals' (Zimmerman, 1995, p. 582). The founder of the Home Birth helpline has confirmed (pers. comm. 16 February 2013) that this reflects her own understanding of 'empowerment'.

There is very little interactional/ interpersonal communication research on either anxiety and distress (for exceptions see Hepburn and Potter, 2007; Whalen and Zimmerman, 1998), or on how 'empowerment' is evidenced within support contexts (but see Pudlinski, 2009; Shaw and Kitzinger, 2012) and what does exist is often based on self-report data (e.g. interviews or questionnaires with callers and/or call-takers), rather than on observation of actual interactions. Research based on self-report data loses 'the specific details' of what happens in helpline encounters, replacing them with 'idealisations about how [such] interaction works' (Heritage, 1984:236).

By contrast, interactional research, such as that using the qualitative method of conversation analysis, avoids the issue of to what extent reports of interactions accurately reflect what actually takes place, as it is based on recordings of naturally occurring interaction. These recordings are transcribed and examined repeatedly in order to provide a detailed and systematic account of the communicative practices which people use in interacting with one another; both to 'produce meaningful action and to interpret the other's meaning' (Drew at al. 2001:59).

Conversation analysis has recently been described as 'the dominant approach to the study of human social interaction across the disciplines of Sociology, Linguistics and Communication' (Stivers and Sidnell, 2012) and it has a long-standing interest in helplines. For instance, much of the early work in conversation analysis by its inventor Harvey Sacks was based on recordings of telephone calls made to a suicide prevention helpline (Sacks, 1995). Since Sacks, a number of studies have attempted to describe how callers and call-takers on various kinds of institutionallyprovided helplines interact, including the classic work on emergency calls (Whalen and Zimmerman, 1990, 1998), and - more recently - calls to a primary health-care 'out-of-hours' service, calls to technical support, to emotional/psychological support and to the emergency services (e.g. Baker at al., 2005; Danby et al., 2005; Drew, 2006; Edwards and Stokoe, 2007; Potter and Hepburn, 2003; Pudlinski, 2002; Raymond and Zimmerman, 2007; Whalen and Zimmerman, 2005).

These studies have looked at a range of issues, including the different 'styles' of call openings across helplines with different remits and different ways of operating (e.g. Danby et al., 2005; 
Edwards and Stokoe, 2007; Potter and Hepburn, 2003); the work callers do to present (in a service appropriate way) the trouble they are seeking help with (Edwards and Potter, 2007); the way in which call-takers offer advice and support (Baker et al., 2005; Leppanen, 1998; Pudlinski, 2002) and the way in which social categories are produced in call-monitoring questions (Wilkinson, 2012).

Although it is more common for conversation analysts to work with collections of data fragments, Schegloff (1987) has highlighted the capacity of conversation analysis for the 'analytic explication of a single fragment of talk' (Schegloff ,1987:101). In these single case studies 'various empirically based analytic resources are drawn on to see how an utterance from an ordinary conversation is put together, what it does, how it works' (Schegloff, 1987:103) and 'much grander themes can often be... clearly seen' (Schegloff, 1987:102). The 'grander themes' already explored in singlecase conversation-analytic studies include: how a therapeutic change is evidenced in interaction (Voutilainen, Perakyla \& Ruusuvuori, 2011), how a patient requests medical intervention (Gill, 2005), how a beauty therapist performs 'emotional labour' (Toerien \& Kitzinger, 2007), how a patient uses medical history taking to launch stories (Stivers and Heritage, 2001) and why a call-taker on an emergency line fails to act when a hysterical caller demands an ambulance for his mother, who subsequently dies (Whalen \& Zimmerman, 1998). In this paper we are studying a single call to explore how the call-taker manages two (sometimes competing) interactional tasks: managing the caller's distress, and also enabling her to act to change the conditions that have created it (what the call-taker would call 'empowerment').

Of direct relevance to the question of managing callers' distress, Whalen and Zimmerman (1998) and Hepburn and Potter (2007) have both shown that there is sometimes a tension between managing the caller's emotionally distressed talk and gathering the necessary information to allow the call-taker to make a decision about whether (in Whalen and Zimmerman's example) the relevant emergency services (police, fire or ambulance) should be despatched, or (in Hepburn and Potter's example) advice or information should be offered, or a referral made to other services.

Of direct relevance to whether and how 'empowerment' is evidenced within support contexts, Pudlinski (2009) has illustrated how actions such as 'encouraging' when 'within a particular sequential and contextual environment can be seen as part and parcel of the activity of empowerment' (2009:441). Similarly, our own earlier work on what positive assessments are being used to do interactionally within helpline support, how they are managed by callers, and what their consequences are for the ongoing interaction, shows that compliments, formulated as positive assessments like 'I admire what you're doing' and 'I think you're doing brilliantly', are one important way a call-taker can accomplish (what the helpline intends by) 'empowerment' (see Shaw and Kitzinger, 2012).

In this paper, then, we draw on a body of existing empirical findings 
from conversation analysis to present a case study of a single Home Birth helpline call in which there is a marked tension between - on the one hand displaying empathetic understanding in response to the caller's troubles-talk about her approaching labour and - on the other hand - supporting the caller in acting to change this distressing situation by arranging an alternative to the hospital birth (the 'problem solution'). We focus on the work the call-taker does to acknowledge and validate the caller's distress, while at the same time ensuring that the caller is confident and knowledgeable enough by the end of the call to be in a position to take action to organise her home birth. Finally, we discuss the implications of these strategies for developing effective practice for services providing emotional and psychological support.

\section{Method}

The data extracts presented in this paper are taken from a conversation of just over 13 minutes duration, made to the Home Birth helpline one of a corpus of 80 calls recorded (in conformity with the requirements of the British Psychological Society's ethical codes of practice) by one calltaker, over a period of twelve months. All calls were transcribed in full using notation adapted from Jefferson (2004), Atkinson and Heritage (1984: ix-xvi) and Hepburn (2004). Names (of people and places) were pseudonymised.

Across the Home Birth helpline corpus as a whole, the single most common reason for calling ( $44 \%$ of the calls) was practical difficulties in arranging a home birth (see Shaw and Kitzinger, 2005). This is also the reason for the call analysed here, but it is distinctive in that the caller (pseudonymised as 'Petra') is due to have her baby (as she says) 'in a couple of days' and is booked in for a hospital birth that she now no longer wishes to have. The perceived difficulty of organising a home birth within a short period of time very late in her pregnancy leads the caller to be notably panicky and distressed in the course of her problem presenation, in a way that callers seeking to organise a home birth before the ninth month of pregnancy are not. This particular call has been chosen because it generates a notable tension for the caller between managing the caller's panicky distressed troubles-talk and giving her the skills, confidence and encouragement she needs to organise her home birth. All of the interactional strategies identified in this single call also occur across the calls in the corpus (as discussed below; also see Shaw and Kitzinger, 2007, 2012). However, the main focus in this paper is an analysis of one particular call in which all of the different strategies appear, so allowing us to present an in-depth and contextual analysis of managing distress and 'empowering' callers (a key benefit of case studies, see Stake, 1995; Flyvbjerg, 2006).

\section{Results}

We will present eight extracts from the one call which is the focus of our analysis here, numbered consecutively in the chronological order in which they were spoken. In order to preserve 
and present the interaction in its sequential order from beginning to end, the analysis is presented in terms of the main phases of the call (from opening and problem presentation, to problem solution and closing) within which the call-taker's strategies for managing the interaction are indicated as they occur. The five interactional strategies to which we want to draw attention are: (i) 'reflective listening' and empathetic responses; (ii) informing; (iii) advising; (iv) offering practical assistance; and (v) complimenting, and these strategies are distributed across the different phases of the call.

\section{'Reflective listening' and empathetic responses during the initial problem presentation phase}

We will focus first on how the call-taker manages the caller's (Petra's) distress during the early stages of the problem presentation phase. Extract 1 shows the opening few moments of the call. Petra sounds panicky, traumatised and anxious; her delivery is breathy, rapid and tearful. In response to the caller's story-prompt at line 1 , Petra launches her problem presentation as a narrative (lines 15-31), telling the call-taker that the baby (her second) is due in two days' time and that the hospital has 'completely screwed up' her care. She goes on to say that she only visited the hospital three weeks earlier, only saw the unit where she is expected to deliver her baby the day before this call, and still doesn't know who her lead midwife is (data not shown due to space constraints). This problem presentation is clearly 'troubles-talk' of the sort analysed by Jefferson and Lee (1981), in the sense of being 'talk about a trouble' (p.399), and it is aligned to as such by the calltaker who moves into alignment as a 'troubles-recipient'.

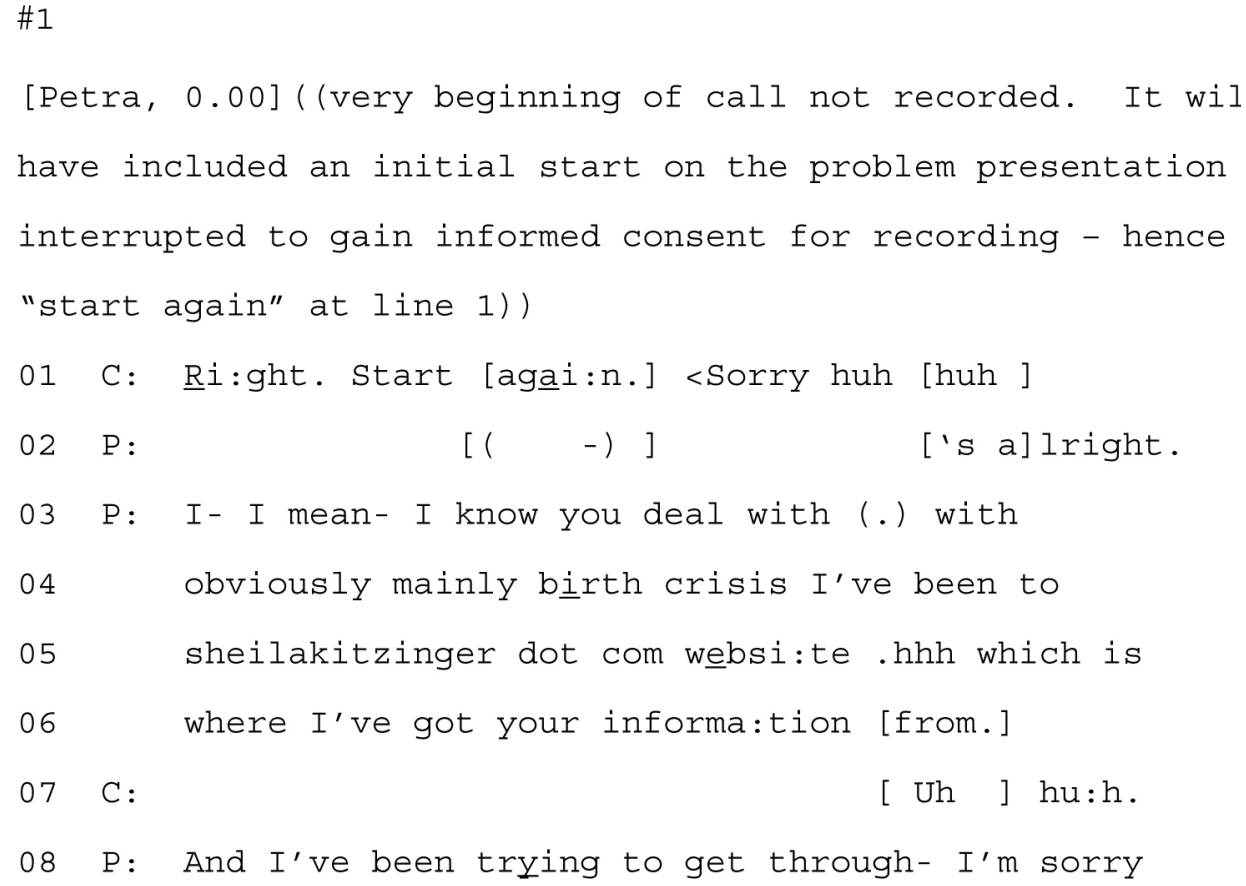




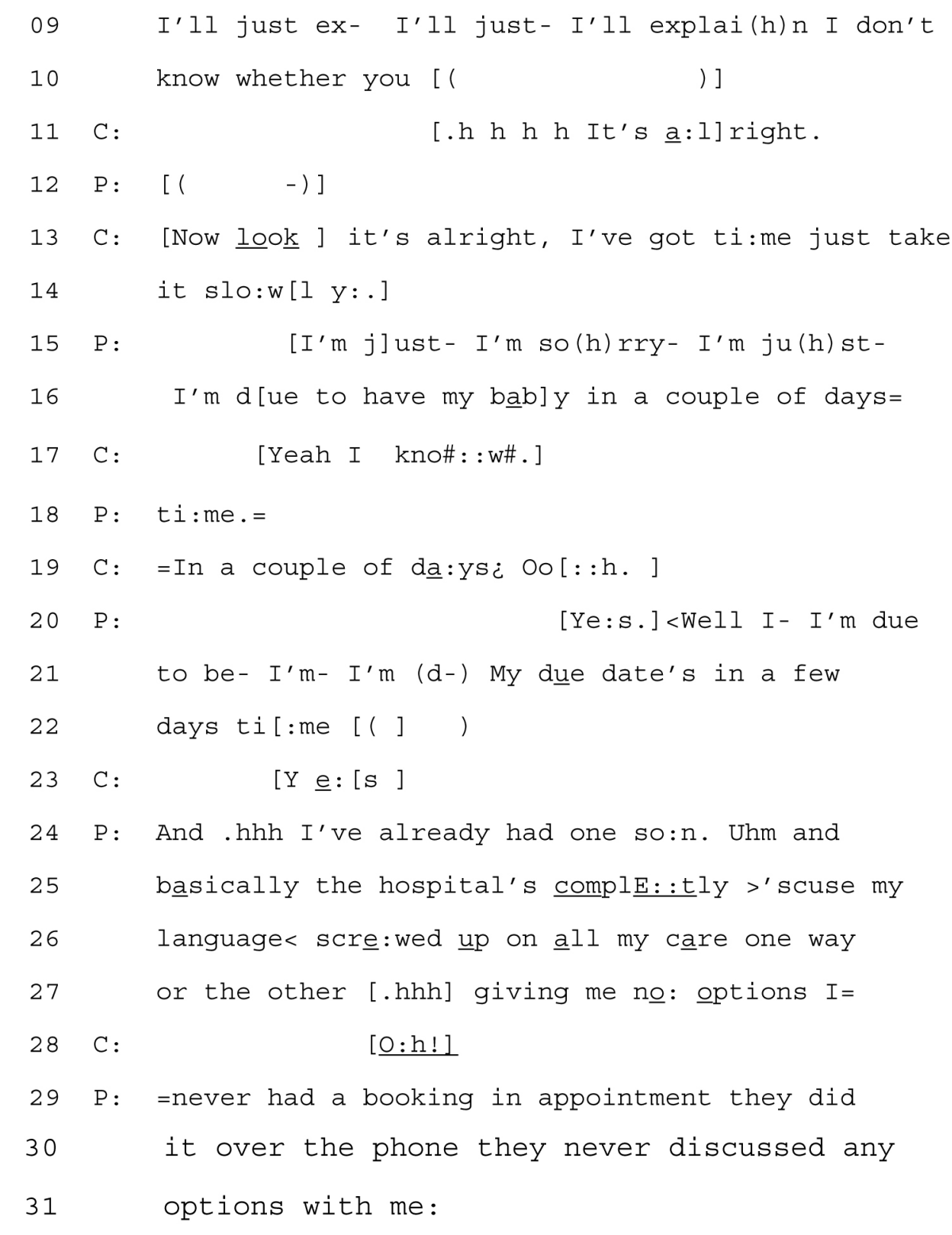

During the caller's opening narrative (lines 15- 31 in Extract 1, continued at lines 41-47 in Extract 2 below), there is minimal uptake from the call-taker. She is providing space for the caller to tell about her problem in her own words (see Shaw and Kitzinger, 2007), offering only minimal responses like continuers ('uh huh', Extract 1, line 7) and receipts ('yes', line 23) (Schegloff, 2007) and reaction tokens (Wilkinson and Kitzinger, 2006; 'Oh!', line 28 which accepts Petra's description of the problem and shows responsive exasperation) and repeats ('in a couple of days', line 19, seeking confirmation of information conveyed). This is what she would call 'reflective listening' (as 
advertised on the webpage to which the caller refers) and what Jefferson and Lee (1981) mean by 'aligned troubles talk recipiency'.

The call-taker also explicitly and overtly offers space for the caller to tell about her problem in her own words, saying (in Extract 1, at lines 13-14) 'I've got time, just take it slowly', in a form comparable to the 'take your times' identified by Hepburn and Potter (2007) in calls to a child protection helpline. Such utterances orient to the caller's struggle to produce talk (in Hepburn and Potter's example because the caller is crying; in ours because the caller is panicking) and signal the call-taker's willingness to make herself available as a recipient of the talk, despite the caller's problems in producing it.

The call-taker also responds with a number of empathetic responses (such as 'That's dreadful' and 'Oh I am sorry', in Extract 2, lines 42 and 46), displaying understanding and empathy (Kitzinger and Kitzinger, 2007).

This form of non-interruptive listening is similar to that in other helplines, where the call-taker is concerned not to bring the problem presentation to 'premature termination (which might cut off important future material) or to premature judgment (which might need to be changed in the course of the call)' (Potter and Hepburn, 2003:211; also see Baker at al., 2005; Kitzinger and Kitzinger, 2007; Pudlinski, 2005; Ruusuvuori, 2005).

Petra's narrative problem presentation is an extended description that builds toward a characterisation of her problem through a string of negative formulations ('giving me no options', Extract 1, line 27, 'never had a booking in appointment', line 29, 'never discussed any options with me', lines $30-31$, as well as others in data too lengthy to show here e.g. 'I've not had any antenatal classes', 'I've not even seen the hospital' and 'I didn't even know where I was going'). These negative formulations constitute what Petra says as a series of 'complaints' against the hospital (cf. Schegloff, 1988 on 'complaining').

Together, the string of negative formulations and the breathy, rapid and tearful quality of Petra's voice convey a sense of urgency and panic. In response, the call-taker has to transform what from Petra's perspective is an urgent and distressing event, into a 'routine call' in which she can offer the caller the support and information she needs to organise her home birth (see Whalen and Zimmerman, 1998). In the next section, we show how having listened empathetically to the problem presentation in the role of a troubles-talk recipient - the call-taker attempts to move the call on to the solution phase by treating the 'trouble' as a problem in need of solution and thus moving from empathetic receipts to informing and advising the caller.

\section{Managing the transition from problem presentation to problem solution - informing and advising}

Extract 2 comes thirty seconds after the end of Extract 1. Petra reports that when she finally saw the hospital where she is supposed to give birth, she thought it was "just absolutely awful' and that she 'can't bear the thought of going there' (lines 43-47). It 
is here, at the first possible place where the problem presentation phase could be complete, that the call-taker moves quickly to an implied solution with an 'informing': she informs the caller of her rights ('Well you don't have to go there', lines 48-49).

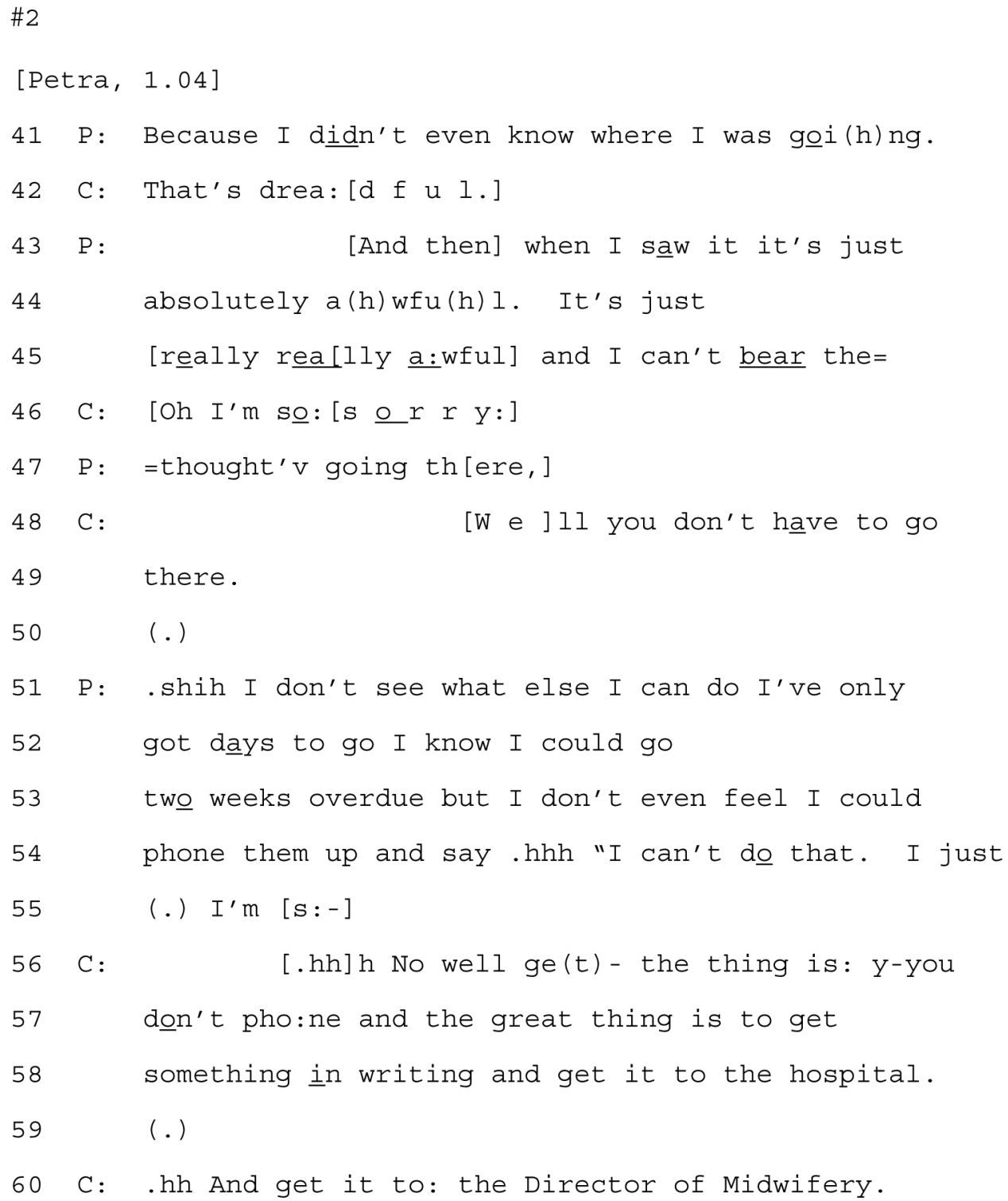

This rapid move from the projectable end of the problem presentation to a 'solution-type' response makes this interaction unlike most other helpline (and emergency) interactions studied, where problem-presentations are regularly followed by 'diagnostic' questions which position the call-taker as help-giver and 'expert' (Baker at al., 2001; Zimmerman, 1992) and create a step-wise sequence from troubles-talk to advising via diagnostic questioning. 
The 'problem solution' here ('well you don't have to go there') is offered - by comparison - early in the interaction. It is also very compact, especially by contrast with the elaborateness of the problem presentation - implying that the complex situation Petra has described has a simple and straightforward solution.

Petra resists this advice. First, she doesn't respond - she is silent at the place where she should talk next (the transition relevance place that opens up at line 50) - perhaps awaiting some expansion as to how 'not going' (something she later says she had considered independently) could be achieved. She further delays a response by sniffing (the .shih at the beginning of line 51) and then explicitly counters the information that she doesn't 'have to go there' by claiming not to have any alternative at this late stage ('I don't see what else I can do', lines 51-52), and by expressing reservations about contacting the hospital with a change of plans (lines 53-54).

In response, the call-taker starts to formulate a directive (at line 56 she seems to be headed towards saying 'get something in writing...'), but cuts off and re-launches what she was going to say with a preface ('the thing is', line 56) which highlights its salience as something to which the caller should attend. What follows works first to endorse the caller's reluctance to 'phone them up' (line 54) - she says 'you don't phone', which treats not phoning as a generically suitable course of action of which the caller's not phoning is an appropriate instance - and then to offer advice as to what she should do in place of phoning: 'get something in writing'. (It is likely that Petra was expressing reservations about contacting the hospital rather than specifically phoning them, but the call-taker has seized on the opportunity offered by her selection of 'phone' as a proxy for 'contact' to pursue an alternative method of contacting them - and one which will provide subsequent 'evidence' [see Extract 3 line 66] for Petra's request.) The advice-giving is considerably mitigated - first by tying it (with 'and', line 57) to the endorsement that phoning is not necessary, and second by the omission of an agent (i.e. not 'you must/should/ought to get something in writing') - perhaps because the call-taker's webpage explicitly claims 'We do not give advice' and she, like many helpline call-takers makes an 'in principle' distinction between giving information (i.e. in this case, that getting something in writing might be an effective way of getting a home birth) and giving advice (i.e. that the caller should get something in writing). Her negotiation of the troublesome boundary between informing and advising is apparent in part through the repairs in this turn and the 'advice' it embodies is furthered by her subsequent specification of the person to whom the writing should be addressed: 'the Director of Midwifery' (line 60). In sum, Extract 2 shows a first move from the call-taker to make the transition from the problempresentation to a (mitigated) 'advicegiving' stage of the call and Petra's resistance to that.

Extract 3 opens with the call-taker's reiterated advice to put something in writing - reminding Petra of her rights over her own body (lines 68-9), which are, as she says, reinforced by government legislation about women's right to choose the place of birth (line 73) 


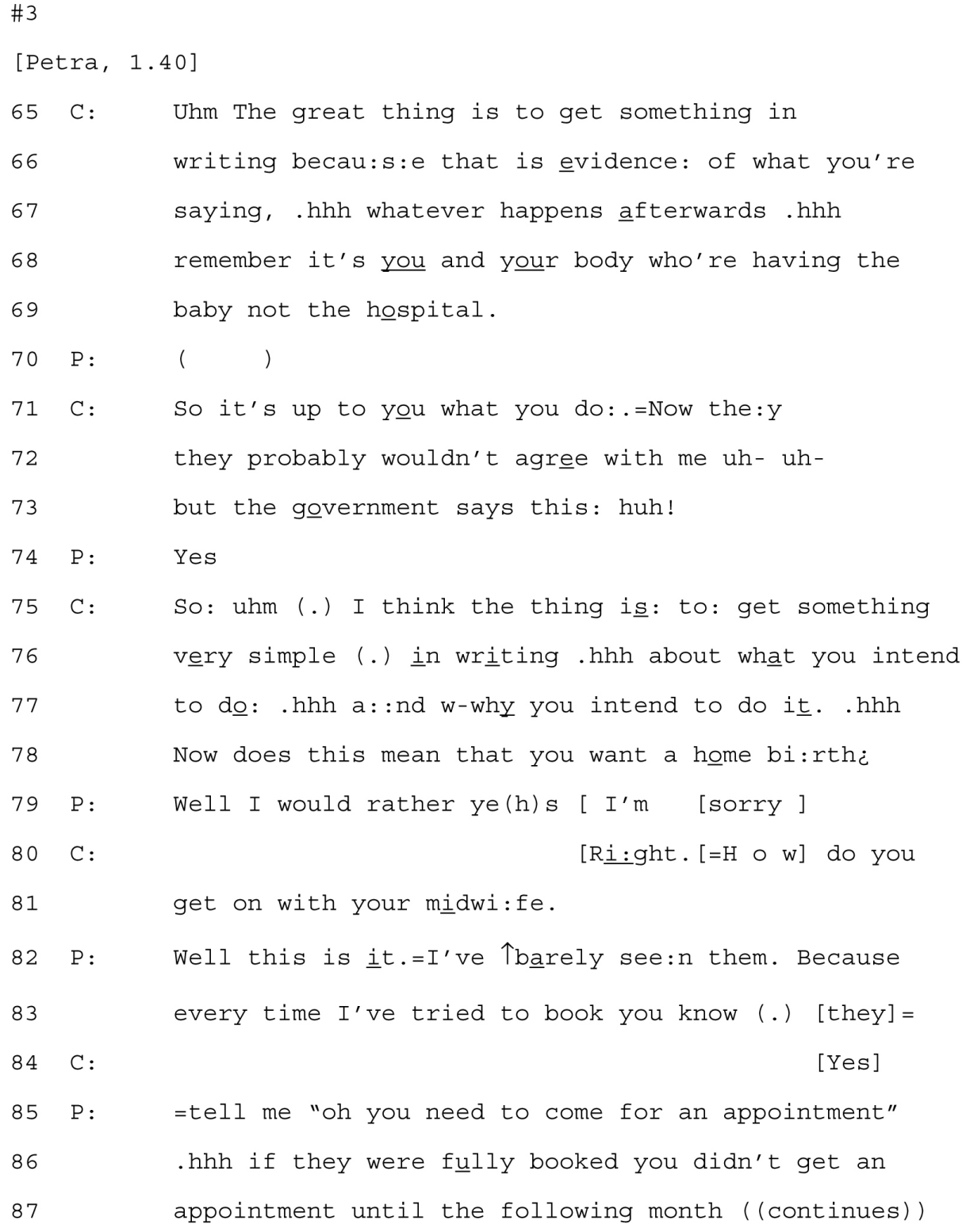

Pursuing the advice to put 'something' in writing, the call-taker checks her understanding that what Petra 'intends to do' (lines 75-78) - instead of having her baby in the 'absolutely awful' (Extract 2 line 44) hospital - is to have a home birth. (Petra hasn't explicitly said this, and alternative options might include going to a different hospital, or to a birthing centre.) If, at line
79, Petra were to confirm that, yes, she does want a home birth, the calltaker would then be in a position to advise her how to inform the hospital of this (presumably first by talking to her midwife, line 81 , if she 'gets on' with her). This next move towards continued advice-giving is blocked by Petra's insistence on continuing with her problem presentation. 
Petra's confirmation of her preference for a home birth is wellprefaced and the actual confirmation token ('yes') is delayed until the end of her turn (line 79). 'Well'prefacing in response to $w h$ - questions operates 'as general alerts that indicate nonstraightforwardness in responding' (Schegloff and Lerner, 2009: 91) and it seems to operate in the same sort of way in response to this yes/no question, the non-straightforwardness being that Petra doesn't believe that what she wants will turn out to be possible. By contrast, the call-taker does believe that it is still possible for Petra to arrange a home birth and begins to elicit background information to assess how best to implement this plan; asking a series of interrogative questions, starting with 'How do you get on with your midwife?' (lines 80 81). In response, Petra again gives nonstraightforward answers that do not deliver the requested information, but instead reiterate her complaints (e.g. that the midwives were 'fully booked', line 86, the 'booking appointment was over the phone', data not shown and that she 'didn't even know what facilities the hospital had', data not shown). While the call-taker is moving onto the practical business of helping Petra to arrange a home birth ('problem solution'), and is no longer aligned as 'troubles-talk recipient' but rather as 'advice giver', Petra continues nonetheless to recycle troubles-talk.

In Extract 4, the call-taker initially returns to the position of a troublestalk recipient and empathetically receipts Petra's account of distress: the 'Ah::::' at line 96 is a long drawnout sympathetic reaction token, and the 'I'm dreadfully sorry' makes explicit her concern for Petra. She then immediately reverts to the role of 'advice-giver', recyling the implied solution (her 'don't go there', line 97, recycles her earlier 'Well you don't have to go there' in Extract 2, lines 4849).

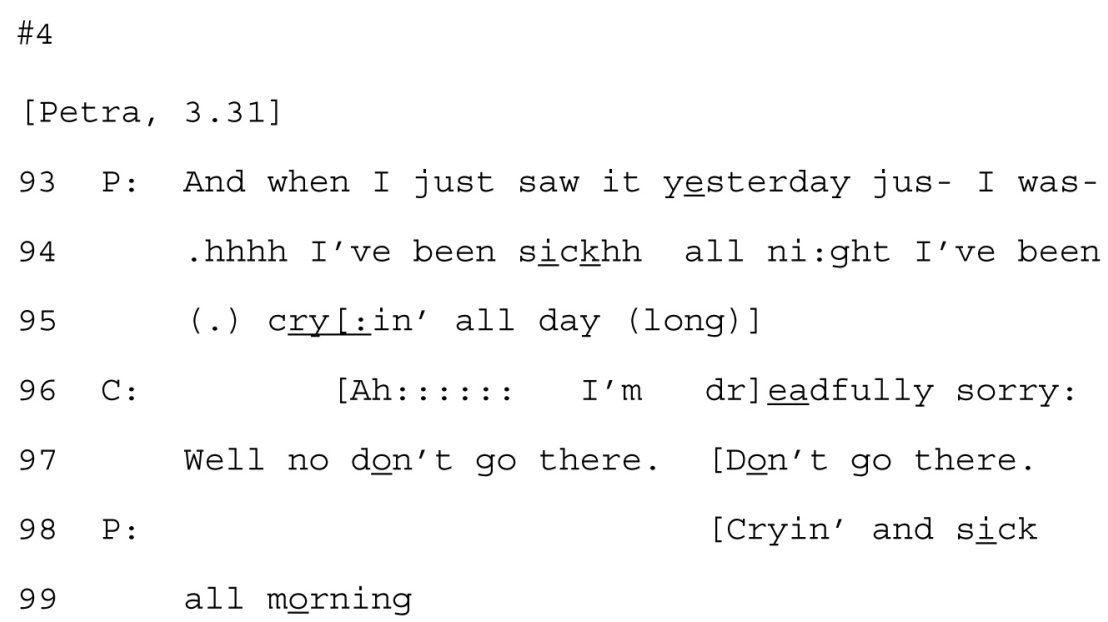

The overlapping talk (at lines 97 and 98) reveals how the call-taker's commitment to 'moving on' to the solution (she is saying - again - that the solution to Petra's distress about a hospital birth is not to go in to the hospital) conflicts with Petra's commitment to troubles-talk (Petra is continuing to provide an account of how distressing she finds the thought 
of going into hospital).

This pattern repeats over the next few minutes - in the interests of space we have not shown all of this data - in that the call-taker asks further information questions in pursuit of arranging a home birth (e.g. 'Was the first birth fairly straightforward?', 'How's the pregnancy been?') and Petra responds with recycled troublestalk. We see this again at the beginning of Extract 5, where Petra describes her horror of going in to hospital (lines 125-126), and the call-taker's 'Okay, don't go' (line 127) again re-does earlier turns (it re-does Extract 2, lines 48-49 and Extract 4, line 97) and is focussed on moving Petra away from her problem presentation/troubles talk to work with her towards planning the solution (a home birth). The first breakthrough comes at lines 128-9 ('But what am I gunna do about having a home birth?').

\#5

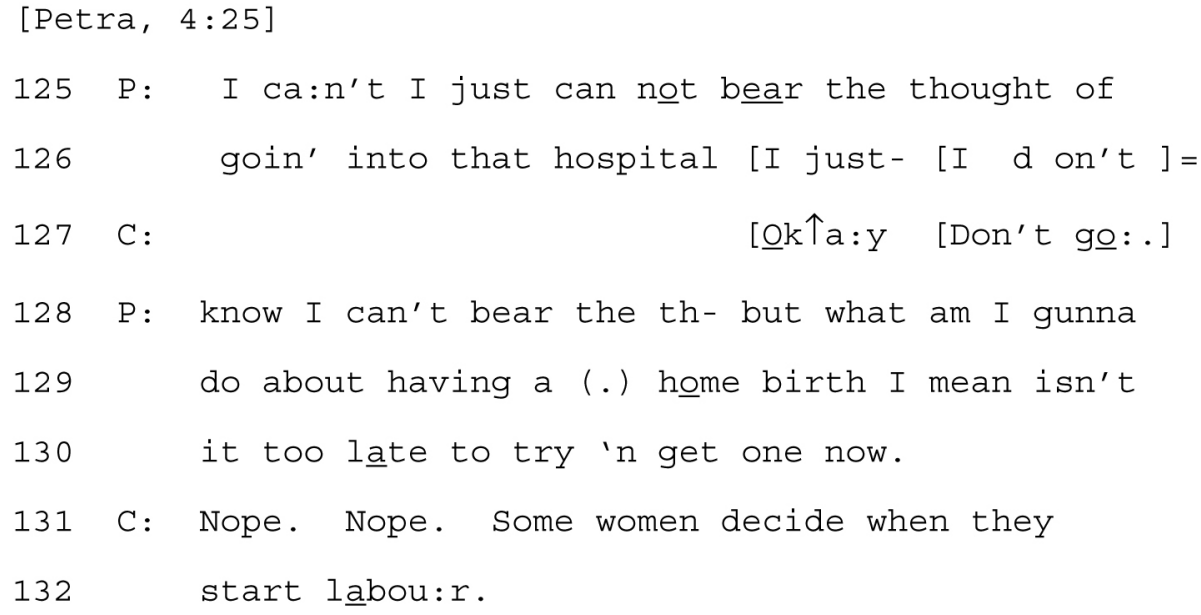

At line 128, Petra self-interrupts a recycling of her troubles, part-way through a repeated complaint, 'I can't bear the thought of going into that hospital'. She self-interrupts in order to ask a question of the calltaker - a question which displays her understanding of a major impediment to following the call-taker's advice: that it's now 'too late' (line 130) to organise a home birth. The call-taker reassures her with an immediate definite and repeated 'Nope' (line 131) that it's not too late and supports this with the claim that some women decide against a planned hospital birth at an even later stage than Petra (not days before an expected delivery date but actually at the beginning of labour, lines 131-2).

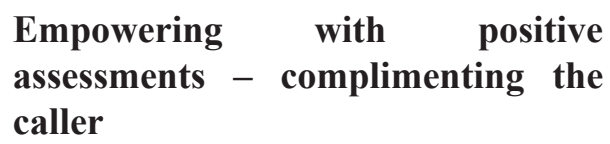

This first breakthrough (in Extract 5) is followed, however by more troublestalk, this time formulated as a complaint about her husband's lack of support and the breakdown in communication with him. She continues with a justification for the legitimacy of her desire for a home birth in the face of claims about its risks. It is in this context that the call-taker compliments Petra ('What a sensible woman you are!', line 202-3). 


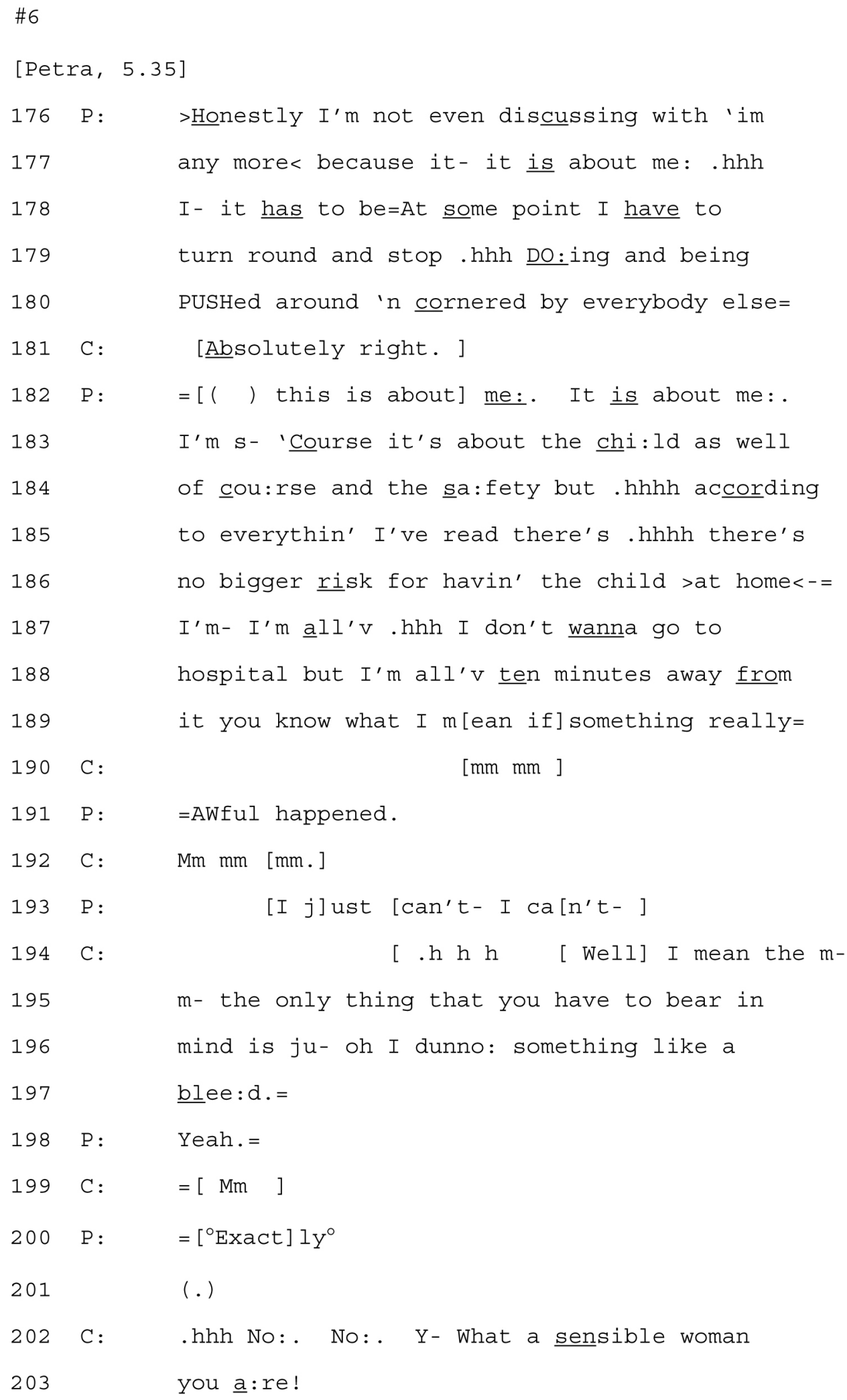


205 P: I just hhh! I just don't feel like they're

206 making me feel like one. and I just so: .hhh

207 I șo: (.) I'm- I feel phhh! >don't get me

208 wrong $I<$ actually feel better for speaking

209 to you 'cause you make me feel like I'm not

210 completely abnormal but I just .hhh I can't

211 bear the thought'v go:ing. I can't go in

212 there. I mean this sounds really

213 stu: [pid but [.hhh [I'm sayin'] =

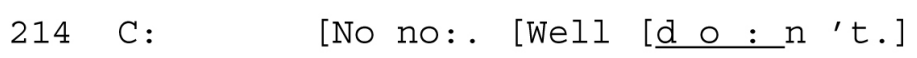

215 P: =to my husband .hhh "The biggest problem

216 you're gonna have right now is ((continues))

In Extract 6, Petra states she would go to hospital if 'something really awful happened' (lines 189-191), which - as a gloss - doesn't engage with any specific contraindications. When one such contra-indication is produced by the call-taker (bleeding between the birth of the baby and the expulsion of the placenta (lines 194-197)), Petra doesn't pursue this (e.g. by asking questions about the statistical probability of such bleeding or by enquiring about other possible contra-indications), but rather treats the call-taker's turn as telling her something she already knew 'yeah exactly' lines 198 and 200). In response, the call-taker's turn initial repeated 'no' (line 202) seems to be working to set aside the contraindications issue with which Petra is declining to engage. As such, the rest of the call-taker's turn ('what a sensible woman you are') comes off as a positive assessment of Petra's earlier talk about her awareness of the possible risk, her willingness to go to hospital if needs be and the speed with which she could do so. These are all things that the call-taker routinely advises women about when they call the helpline and her assessment serves as an acknowledgment that Petra is presenting herself as knowledgeable, rational and not a risk-taker.

Compliments are very common on the Home Birth helpline. In earlier research we found that in around three quarters of the 80 calls the call-taker makes at least one complimentary positive assessment of the caller or her actions (e.g. 'You're a brave woman,' 'You're doing brilliantly,' 'You're a heroine,' 'I admire what you're doing', Shaw and Kitzinger, 2012). Our analysis found that these turns regularly: 'do more than simply provide positive assessments of callers and their courses of action: they support and encourage them in their 
plans, under circumstances in which others - usually healthcare teams but sometimes also partners or family members - are not supporting their plans for a home birth. For women phoning a helpline for assistance with arranging home births, it is this support - and its implications for their real-world actions (rather than the complimenting action the turn may also hearably carry) that is most salient.' (Shaw and Kitzinger, 2012: 233).

In the Home Birth helpline corpus, more than half of all the complimentary positive assessments made of the callers by the call-taker are accepted (usually with 'thank you'). We have shown that one way of understanding the use of compliments is as the attempt, by the call-taker, to implement and embody in her own practice, the theoretical construct of 'empowerment' that she believes to be crucial to her work. In particular, 'compliments encourage callers to believe that they have the skills/ qualities needed to plan a home birth in the face of opposition or obstruction (they are vocal, strong, persistent, brilliant, courageous, confident, have a lot of grit, have what it takes, and so on)' (Shaw and Kitzinger, 2012: 236). In accepting a compliment, a caller accepts that she is able to plan her home birth - and hence has been 'empowered' by the call-taker. Here, however, Petra's compliment response (lines 205-206) is neither acceptance nor outright rejection. Instead, she continues to complain about others' attitude to her, accepting the compliment only to the extent of acknowledging that the call-taker has allowed her to feel 'not completely abnormal' (lines 209210). There is a second compliment in the closing moments of the call
('You're a courageous woman' Extract 8 lines 432-3 below), which Petra does not reject (although her 'thank you' is ambiguous as to whether she is receipting the compliment or thanking the caller for the call as a whole).

\section{Advising and offering practical assistance in the problem-solution phase}

We have seen Petra's repeated troublestalk about her terror of giving birth in hospital and the call-taker's repeated advice not to do so. This advice is conveyed in an increasingly reduced form as the call progresses: the initial version 'you don't have to go there' (in Extract 2, lines 48-49), becomes 'don't go there' (in Extract 4, line 97), then 'don't go' (in Extract 5, line 127), and finally 'well don't' (Extract 6, line 214).

The initial 'advice' in this call occurs (as we have seen) very early onafter only a minute of recorded talk. It is, perhaps, offered 'prematurely' (Jefferson and Lee, 1992:531) insofar as it comes in a slot where other actions are more common in counselling settings: actions such as exploring why the caller can't bear the thought of going to the hospital, and whether there are practical changes that the hospital could make (e.g. in other calls, offering female-only care, a private room, guaranteed use of a pool), or that the caller could organise (e.g. in other calls, hiring a doula to accompany her, taking in her own aromatherapy oils and meditation tapes). It may be that the call-taker is seeking to avoid 'why' questions (like 'why can't you bear the thought?') which are often heard and reacted to as challenging the position 
the addressee is taking (Bolden and Robinson, 2011). However, since hospital births are commonplace in the UK $(98 \%$ of births take place in hospitals, Office for National Statistics, 2010), Petra must already have had the experience of finding her panicky reaction to a hospital birth questioned and challenged by others (including, as she says, her husband, Extract 6). It may also seem to her that the call-taker has too readily accepted her feelings on the matter without adequately exploring or understanding them. (In fact, the call-taker regularly deals with distress and trauma relating to hospital experiences and across all the calls in the corpus she readily accepts that women find hospitals frightening.) Only after almost eight minutes of interaction, following yet another recycling of Petra's feelings about the impossibility of having her baby in the hospital (accepted by the call-taker with a couple of quiet 'no's), Petra asks - seriously - 'So how do I go about...' (Extract 7 below, line 262), finally cooperating with the calltaker's attempts to move the call onto the problem solution phase.

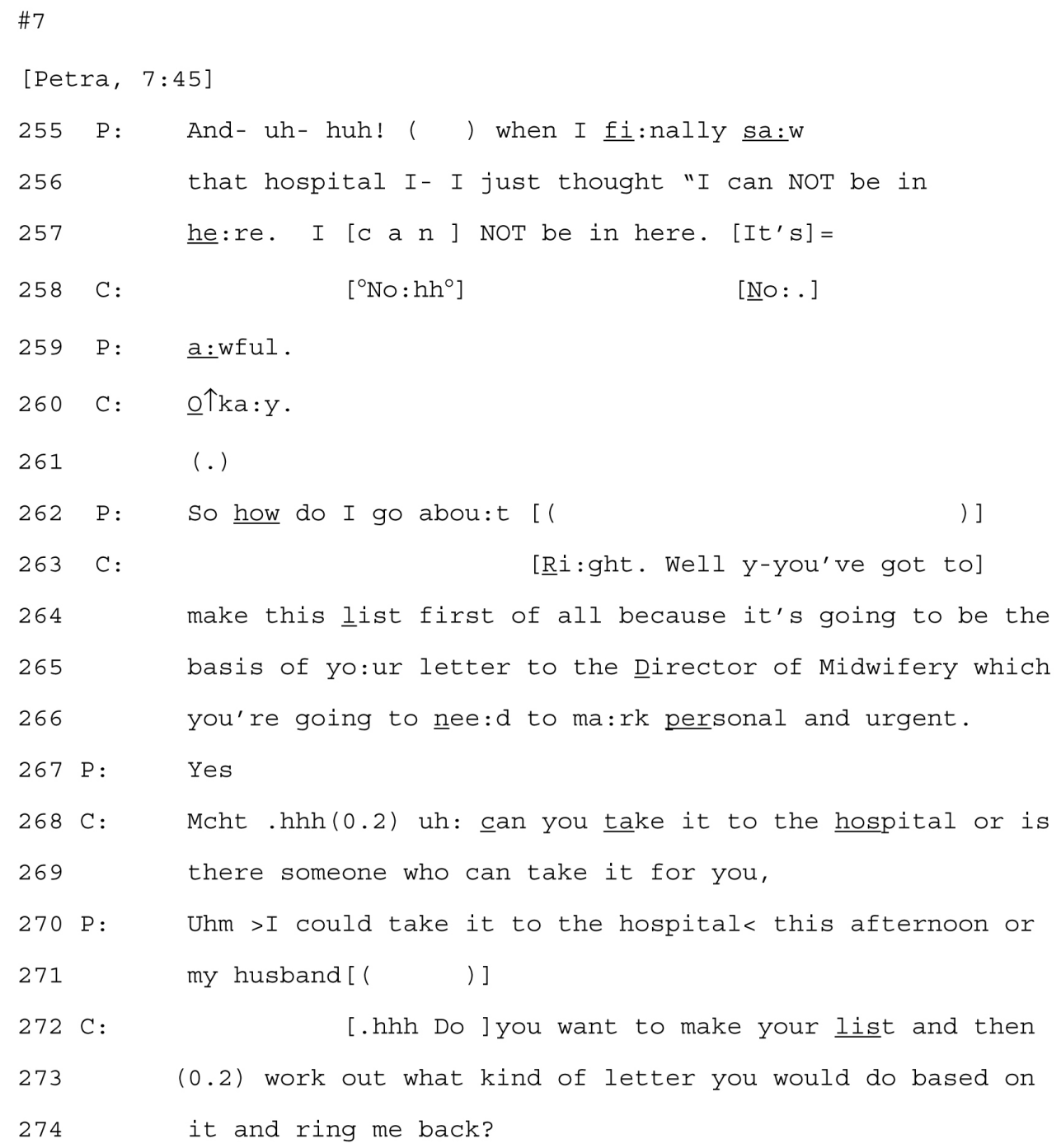


Petra's question 'So how do I go about...' is in some ways the 'same' question that she asked earlier (in Extract 5, lines 128-129, four and a half minutes into the call), but very differently formulated. Whereas the earlier question supposes she cannot have a home birth and raises an obstacle to it, this question supposes that she can and is a serious request for information about how to arrange it. In response, the call-taker reiterates her suggestion that Petra makes a list about what is important to her for her labour, as the basis for her letter to the
Director of Midwifery; sorts out how the letter is to be delivered; and then more or less dictates it to Petra (data not shown).

After (a four-minute) discussion of what to put in the letter, Petra thanks the call-taker and says 'I will do this' (i.e. write the letter) (Extract 8, line 431). The call-taker ratifies the move to close with an appreciation of Petra's call and a compliment designed to characterise the caller as able to cope, despite her fears ('you're a courageous woman', Extract 8, lines 432-433).

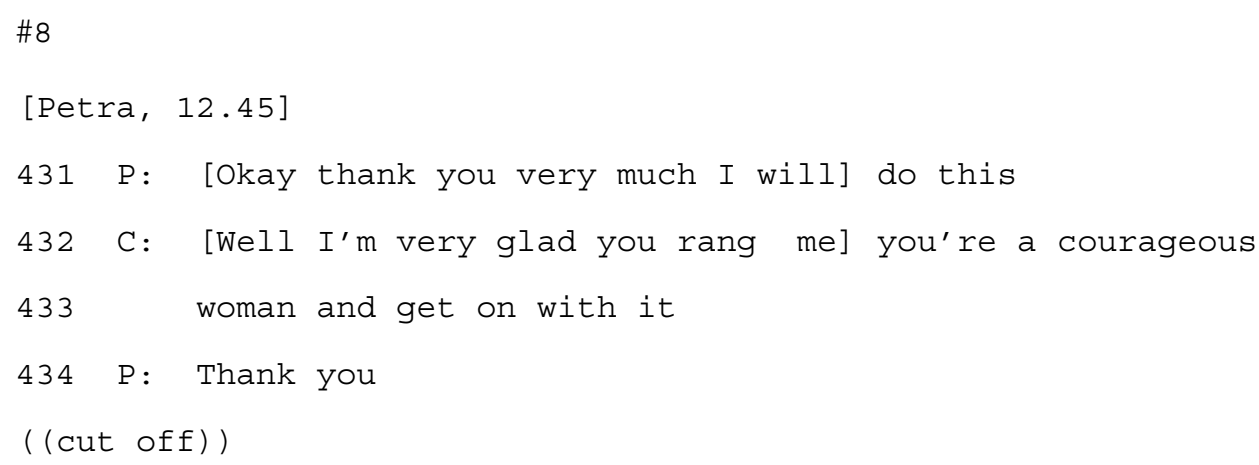

The overlap of the compliment turn with the caller's continued turn about her planned next action and the calltaker's speedy move on to the relevant next action, terminating the call ('and get on with it', line 433), leaves no space for Petra to respond to the compliment itself. Petra's 'thank you' seals the call-taker's move to call-closing on an 'upbeat' and positive note.

By the end of this call, then, Petra is able to control her own disabling panic and to begin to put in motion a positive plan of action for achieving a home birth. This is facilitated by the calltaker's practical help in drafting a letter and by her supportive and positive assessment of Petra's attitude.

\section{Discussion}

There is a tension in this call (as in many within the corpus) between the caller's emotionally distressed 'troubles talk' and the call-taker's need to 'manage the encounter and mobilize an organisational response' (Whalen and Zimmerman, 1998:143) to enable the caller to act practically to improve her situation. Unlike helplines such as the emergency services, where the 'organisational response' means the call-taker has to send out the appropriate emergency service, in these calls it is the caller (not the call-taker) who has to act; all the call-taker can do is support, advise 
and - crucially - 'empower' the caller to act on her own behalf.

In this analysis we have shown how this is done moment-by-moment in the course of the interaction. For instance, we have shown how - after initially empathising with the 'troubles talk' - the call-taker informed the caller of her rights, how she passed on the information needed to exercise her choice to birth at home (e.g. that the most straightforward way to request a home birth is by writing directly to the Director of Midwifery), how she provided practical assistance (e.g. with the drafting of the letter) and how she complimented the caller's behaviour and planned actions. These strategies occur across the Home Birth helpline corpus as a whole (Shaw and Kitzinger, 2007; 2012) and our analysis significantly develops the early work on the rejection of advice following troubles-talk (Jefferson \& Lee, 1981; 1992) by showing the shift from rejection to acceptance over the course of the sequential unfolding of the interaction.

Insofar as other professionals working in psychological, counselling, therapeutic and helpline contexts also adhere to the theoretical concept of 'empowerment', this research offers a possible illustration of what the concept might look like in action, and as such is useful in counsellor education - and indeed has been so used. For example, the findings from this research on the Home Birth helpline have been applied to training and practice in a number of ways. First, summaries of findings and selected transcripts have been offered to the call-taker as a means to establish a dialogue about her practice and the constraints under which she operates. Second, training workshops have been developed with call-takers for this and for other birth-related helplines (Kitzinger \& Kitzinger, 2007; Kitzinger, 2011), to facilitate the exploration of the relational skills involved in doing helpline work skills which call-takers themselves are unlikely to be able to articulate, but which are fundamental to the encounter. In these workshops, actual recordings of helpline calls are paused at key places in the course of the unfolding interaction and trainees are asked to say whatever they would say next (if they were the call-taker). The calls are then played on to see what the call-taker actually said. The call analysed here has been used in training specifically to alert call-takers to the tension that can exist between positioning themselves as aligned troubles-talk recipients (empathising with the caller's difficult situation) and 'advice givers' for whom the 'trouble' is a problem for which they want to help the caller find a solution. In this way, training workshops can heighten call-takers' awareness of alternatives, and of the interactional dilemmas that are present in calls (Kitzinger 2011).

In sum, our case study contributes to the field of health communication an in-depth analysis of the tension that can exist between offering empathetic responses and offering advice in response to a troubles-telling and shows how this is managed over the course of a single interaction. 


\section{References}

Atkinson, J. and Heritage, J. (1984) Transcription notation. In J. Atkinson and J. Heritage (Eds.) Structures of Social Action: Studies in Conversation Analysis (pp. ix-xvi). Cambridge: Cambridge University Press.

Baker, C., Emmison, M. and Firth, A. (2001) Discovering order in opening sequences: calls to a software helpline. In A.W. McHoul and M. Rapley (eds.) How to Analyse Talk in Institutional Settings: A Casebook of Methods (pp.41-56). London: Continuum.

Baker, C,. Emmison, M.and Firth, A. (2005) (eds.) Calling for Help: Language and social interaction in telephone helplines. (pp.39-62). Amsterdam/Philadelphia: John Benjamins Publishing Company.

Baker, C., Emmison, M. and Firth, A. (2005) Calibrating for competence in calls to technical support. In C. Baker, M. Emmison and A. Firth (eds.) Calling for Help: Language and social interaction in telephone helplines. (pp.39-62). Amsterdam/ Philadelphia: John Benjamins Publishing Company.

Bolden, G. and Robinson, J. D. (2011) Soliciting accounts with why-interrogatives in conversation. Journal of Communication. 61 (1 ): 94-119.

British Psychological Society (2000) Code of Conduct, Ethical Principles and Guideline. Leicester: British Psychological Society.

British Sociological Association (2002) Statement of Ethical Practice. London: British Sociological Association.

Danby, S., Baker, C. and Emmison, M. (2005) Four observations on openings in calls to Kids Help Line. In C.D. Baker, M. Emmison and A. Firth (Eds.) Calling for Help: Language and social interaction in telephone helplines (pp.133-151). Amsterdam/Philadelphia: John Benjamins Publishing Company.

Drew, P. (2006) Mis-alignments in 'after-hours' calls to a British GP's practice: a study in telephone medicine. In J. Heritage and D. Maynard (Eds.) Communication in medical care: interaction between primary care physicians and patients.

Cambridge: Cambridge University Press.

Drew, P., Chatwin, J. and Collins, S. (2001) Conversation analysis: a method for research into interactions between patients and health-care professionals. Health Expectations, 4:58-70.

Drew, P. and Heritage, J. (1992) Talk at work: interaction in institutional settings. Cambridge: Cambridge University Press.

Edwards, D. and Stokoe, E. (2007) Self-help in calls for help with problem neighbours. Research on Language and Social Interaction, 40(1):9-32.

Flyvbjerg, B. (2006) Five misunderstandings about case-study research. Qualitative Inquiry, 12(2):219-245.

Gill, V.T. (2005) Patient 'demand' for medical interventions: exerting pressure for an offer in a primary care clinic visit. Research on Language and Social Interaction, 38 (4), 451-479.

Hepburn, A. (2004) Crying: notes on description, transcription and interaction. Research on Language and Social Interaction, 37(3):215-290.

Hepburn, A. and Potter, J. (2007) Crying receipts: time, empathy and institutional 
practice. Research on Language and Social Interaction, 40(1):89-116.

Heritage, J. (1984). Conversation analysis. In J. Heritage, Garfinkel and Ethnomethodology (pp. 233-244). Cambridge, England: Polity Press.

Jefferson, G. (2004) Glossary of transcription symbols with an introduction. In Lerner, G. H. (Ed.) Conversation Analysis: Studies From The First Generation (Pragmatics and Beyond New Series) (pp. 13-31). Amsterdam: John Benjamins Publishing Company.

Jefferson, G. \& Lee, J.R.E. (1981) The rejection of advice: Managing the problematic convergence of a 'troubles-telling' and a 'service encounter', Journal of Pragmatics 5: 399-422.

Jefferson, G. and Lee, J.R.E. (1992) The rejection of advice: managing the problematic convergence of a 'Troubles Telling' and a 'Service Encounter', in P.Drew and J. Heritage (eds.) Talk at Work: Interaction in Institutional Settings (pp.521-548). Cambridge: Cambridge University Press.

Kitzinger, S. (2011) Working with childbirth helplines: The contributions and limitations of conversation analysis. In Antaki, C. (ed.) Applied Conversation Analysis: Intervention and Change in Institutional Talk. Houndmills: Palgrave Macmillan.

Kitzinger, S. and Kitzinger, S. (2007) Birth trauma: Talking with women and the value of conversation analysis, British Journal of Midwifery 15(5): 256-264. Kitzinger, S. (2004) The New Experience of Childbirth. Orion: London. Leppanen, V. (1998) The straightforwardness of advice: advice giving in interactions between Swedish district nurses and patients. Research on Language and Social Interaction, 31:209-239.

Leppanen, V. (2005) Callers presentations of problems in telephone calls to a Swedish primary care. In C.D. Baker, M. Emmison and A. Firth (Eds.) Calling for Help: Language and social interaction in telephone helplines (pp.177-205). Amsterdam/Philadelphia: John Benjamins Publishing Company. Office for National Statistics (ONS) (2011) Live Births in England and Wales by characteristics of birth, 2010 Statircial Bulletin (10 November 2011). (Available at http://www.ons.gov.uk/ons/dcp171778_241936.pdf) (Accessed 3/10/2012)

Potter, J. and Hepburn, A. (2003) 'I'm a bit concerned' - early actions and psychological constructions in a child protection helpline. Research on Language and Social Interaction, 36(3):197-240.

Pudlinski, C. (2002) Accepting and rejecting advice as competent peers: caller dilemmas on a warm line. Discourse Studies, 4(4):481-500.

Pudlinksi, C. (2009) Empowerment on warm lines: microanalytical explorations of peer encouragement. Text \& Talk, 29-4:439-458.

Raymond, G. and Zimmerman, D.H. (2007) Rights and responsibilities in calls for help: the case of the mountain glade fire. Research on Language and Social Interaction, 40(1):33-62.

Ruusuvuori, J. (2005) 'Empathy' and 'sympathy' in action: attending to patients' troubles in Finnish homeopathic and general practice consultations. Social Psychology Quarterly 68(3):204-222. 
Sacks, H. (1995). Lectures on Conversation, Volumes. 1 and 2, G.Jefferson (Ed.) Cambridge, MA: Blackwell.

Schegloff, E.A. (1987) Analyzing single episodes of interaction: an exercise in conversation analysis. Social Psychology Quarterly, 50(2):101-114.

Schegloff, E.A. (1988) Goffman and the analysis of conversation. In P. Drew and A. Wootton (eds.) Erving Goffman: Exploring the Interaction Order. Cambridge: Polity Press, pp. 89-135.

Schegloff, E.A. (2007) Sequence Organization in Interaction. Cambridge: Cambridge University Press.

Schegloff, E.A. \& Lerner, G.H. 2009. Beginning to respond: Well-prefaced responses to wh-questions, Research on Language and Social Interaction 42: 91115 .

Shaw (2007) Problem presentation and advice-gicing on a Home Birth helpline: a femininst conversation analytic study, Feminism \& Psychology, 17(2):203-213. Shaw and Kitzinger (2005) Calls to a home birth helpline: empowerment in childbirth, Social Science and Medicine, 61(11): 2374-2383.

Shaw and Kitzinger (2007) Problem presentation and advice-giving on a Home Birth Helpline: A feminist conversation analytic study. Feminism and Psychology, 17 (2): 203-213.

Shaw and Kitzinger (2012) Compliments on a Home Birth helpline. Research on Language and Social Interaction. 45:3, 213-244.

Stake, R.E. (1995) The art of case Study Research. London: Sage.

Stivers, T and Sidnell . J (2012) Handbook of Conversation Analysis. London: Blackwell.

Stivers, T. and Heritage, J. (2001) Breaking the sequential mold: Answering more than the question' during comprehensive history taking. Text 21(1/2), pp. 151-185.

Toerien, M. and Author (2007) Emotional labour in action: navigating multiple involvements in the beauty salon. Sociology, 41(4):645-662.

Voutilainen, L., Perakyla, A. \& Ruusuvuori, J. 2011. Therapeutic change in interaction: Conversation analysis of a transforming sequence. Psychotherapy Research, 21(3):348-365.

Whalen, M. and Zimmerman, D.H. (1987) Sequential and institutional calls for help. Social Psychology Quarterly, 50(2):172-185.

Whalen, M. and Zimmerman, D.H. (1990) Describing trouble: practical epistemology in citizen calls to the police. Language in Society, 19:465-492. Whalen, J. and Zimmerman, D.H. (1998) Observations on the display and management of emotion in naturally occurring activities: the case of 'hysteria' in calls to 911. Social Psychology Quarterly, 61: 141-159.

Whalen, J. and Zimmerman, D.H. (2005) Working a call: multiparty management and interactional infrastructure in calls for help. In C.D. Baker, M. Emmison and A. Firth (Eds.) Calling for Help: Language and social interaction in telephone helplines (pp.309-345). Amsterdam/Philadelphia: John Benjamins Publishing Company.

Wilkinson, S. (2011) Constructing ethnicity statistics in talk-in-interaction: 
28 | IRSR Volume 3, Issue 2, June 2013

Producing the White European', Discourse \& Society 22(3): 343-361.

Wilkinson, S. \& Kitzinger, C. (2006) Surprise as an interactional achievement:

Reaction tokens in conversation, Social Psychology Quarterly 69(2): 150-182.

Zimmerman, M. A. (1995) Psychological empowerment: Issues and illustrations. American Journal of Community Psychology, 23, 581-599. 